\title{
PERSONAL NEED FOR STRUCTURE, THE EINSTELLUNG TASK, AND THE EFFECTS OF STRESS
}

\author{
P. Wesley Schultz ${ }^{1}$ and Alan Searleman Department of Psychology, St Lawrence \\ University ( Received 2 June 1997)
}

\begin{abstract}
Summary-We examine the relationship between the personality variable of Personal Need for Structure (PNS) and problem solving on the Einstellung water-jar task. The Einstellung task was administered under stressful and nonstressful conditions. Results from 172 participants showed the predicted interaction between PNS and experimentally-induced stress: Participants higher in PNS were more likely to develop a mental set under stressful conditions, while no significant relationship was found between PNS and set development under nonstressful conditions. PNS was not related to perseveration on the Einstellung task.

regardless of experimental condition. These findings are consistent with recent research on the importance of contextual activation of personality. (C) 1998 Elsevier Science Ltd. All rights reserved
\end{abstract}

Keywords: personal need for structure, Einstellung, water-jar task. perseveration. mental set. stress

The world is a complex, information-rich environment, and humans possess only a limited information-processing capability. A large body of psychological research has examined the ways in which humans structure, simplify, and organize information in an attempt to reduce the amount of processing necessary to function in an otherwise overwhelming world. These strategies include the use of heuristics, schemas, stereotypes, and scripts, as well as a wide variety of avoidance strategies (Fiske \& Taylor, 1991; Kahneman, 1973; Neuberg \& Newsom, 1993; Pashler, 1992). Recently, personality researchers have begun to examine individual differences in the tendency to structure information.

One recently-developed instrument is the Personal Need for Structure Scale (PNS) (Neuberg \& Newsom, 1993; Neuberg et al., in press; Thompson et al., 1989). This 12-item scale is intended to measure individual differences in preference for cognitive simplicity and structure. Scale scores represent the degree to which people are dispositionally motivated to structure their worlds in simple and unambiguous ways. An individual high in PNS would prefer structure and clarity in most situations, with ambiguity and gray areas proving irritating and annoying (Thompson et al., 1994). Because the PNS scale is relatively new, only a handful of studies have been published that examine the characteristics of high and low PNS scorers. The research that has been published suggests that high PNS is associated with a greater tendency to stereotype (Neuberg \& Newsom, 1993, study l; Schaller et al., 1995), a greater tendency to categorize new information (Moskowitz, 1993), a tendency to form less complex categories for objects (Neuberg \& Newsom, 1993, study 3), and a tendency to complete participation in a research project earlier (Neuberg \& Newsom, 1993 study 5). Neuberg and Newsom (1993, studies 1 and 2) found scores on the PNS scale to correlate positively with authoritarianism ( $r=0.28$ and $r=0.38$ in two independent samples respectively), Rokeach's (1960) digomatism scale ( $r=0.35$ ), and

\footnotetext{
${ }^{1}$ To whom all correspondence should be addressed at: Department of Psychology, California State University. San Marcos. CA 92096, U.S.A. E-mail:

PSCH $(<$ ilmailhostl.csusm.edu
} 
Gough's (1952) rigidity scale ( $r=0.48, r=0.60, r=0.58$ in three independent samples). Neuberg and Newsom (1993) also report negative relation- ships between PNS scores and Cacioppo and Petty's (1982) need for cognition scale ( $r=-0.23)$, and John et al. (1991) NEO measure of openness $(r=-0.42)$. These findings suggest that the PNS scale does in fact measure individual differences in the desire for structure.

A recent study of Brand et al. (1995) examined the effects of stress (induced by noise) on information processing for people high and low in rigidity-a positive correlate of PNS. Rigidity was measured using a translated (the study was conducted in the Netherlands) version of CPI flexibility (Gough \& Bradley, 1997). CPI flexibility measures the degree to which a person likes change and variety and is easily bored by routine and everyday experience (Gough \& Bradley, 1997; McCrae et al., 1993). Brand et al. (1995) found that stress produced detrimental effects on performance only for certain people-under noisy conditions, the rigid participants responded faster but made more errors than the nonrigid participants. This effect was found for two memory tasks and for the Stroop color-word interference task.

Similar effects have been found for the related construct of Need for Closure. Kruglanski and his colleagues (Ford \& Kruglanski, 1995; Kruglanski, 1989; Kruglanski \& Freund, 1983) have conceptualized the need for closure as a situationally induced motive that is activated under such acute circumstances as time pressure to reach a decision (Freund et al., 1985; Jamieson \& Zanna, 1989). Kruglanski argues that a person's tendency to "freeze" upon a particular belief is directly related to individual differences in need for cognitive structure and a person's fear of invalidity (i.e., the perceived cost of committing an error in judgment). In a series of studies, Kruglanski and his colleagues have demonstrated that "freezing" occurs when a person high in need for cognitive structure (either because of their personality or experimentally induced) is placed in conditions in which the fear of invalidity is activated.

The studies cited above suggest that, when properly activated, individual differences in need for structure may be related to a greater tendency to develop mental sets. In addition, individual differences in need for structure may predict the tendency to perseverate in the use of these mental sets, although there is little prior research to support this prediction. To explicitly test these hypotheses, we examined the relationship between PNS and problem-solving under stressful and nonstressful conditions, using the classic Einstellung water-jar task. We predicted that under stressful conditions, subjects high in PNS would be more likely than subjects low in PNS to develop a mental set when solving a series of problems that all had a common solution.

\section{METHOD}

\section{Participants}

Participants in the experiment were 172 college undergraduates who were recruited from general psychology classes. As an incentive for participating, all the students received bonus points towards earning higher grades. 
Experimental materials

Personal need for structure. As mentioned earlier, this is a relatively new scale that measures the degree to which a person desires simple structure (Neuberg \& Newsom, 1993; Thompson et al., 1989). The scale consists of 12 items in which participants are asked to rate, on a Likert scale, the degree to which they agree or disagree with each statement. We used a seven-point scale ranging from "Strongly Disagree" (I) to "Strongly Agree" (7) with a neutral point (4). An example of a scale item is "I don't like situations that are uncertain". Four of the scale items are reverse scored. In the present study, the alpha reliability coefficient for the PNS scale was 0.77 .

Einste/lung. We used the Einstellung task to measure the development and perseveration of a mental set. Maier (1930) described the Einstellung phenomenon, in which participants first became habituated to using a particular problem-solving approach, and then subsequently overlooked simpler solutions when the problem conditions changed. Luchins (1942) (Luchins \& Luchins, 1959, 1994) have conducted a long-term series of studies using water-jar problems to study the development of mental sets. Their procedure is to present people with several paper-and-pencil problems involving the manipulation of three jars of various sizes. The task is to figure out how to use the jars to measure out a certain amount of water. After solving a number of problems that used the same sequence of operations for solution, most participants developed a mental set and used the same sequence of operations for solution, most participants developed a mental set and tended to use (or try to use) the same set solution even though the problem changed and the set solution either no longer worked or was not optimal.

Although there is a large body of research investigating the water-jar task, almost all of it explores variations of the procedure that lead to either more or less perseveration (Luchins \& Luchins, 1959, 1989).

Table I. Einstellung water-jar problems

\begin{tabular}{|l|c|c|c|c|}
\hline Experimental phase & Jar A & Jar B & Jar C & $\begin{array}{c}\text { Goal to } \\
\text { obtain }\end{array}$ \\
\hline (1) Example & 13 & 39 & 3 & 30 \\
\hline (2) Sample problem & 42 & 37 & 5 & 10 \\
\hline (3) Set problems & 31 & 61 & 12 & 6 \\
\hline & 20 & 67 & 13 & 21 \\
\hline & 18 & 59 & 16 & 9 \\
\hline & 22 & 57 & JO & 15 \\
\hline & 23 & 76 & 16 & 21 \\
\hline & 28 & 83 & 13 & 29 \\
\hline & 18 & 43 & 10 & 5 \\
\hline & 24 & 52 & 3 & 22 \\
\hline & 19 & 42 & 3 & 17 \\
\hline & 20 & 59 & 4 & $3 \mathrm{I}$ \\
\hline
\end{tabular}

While some research has examined individual differences in Einstellung perseveration (Luchins \& Luchins, 1982, 1984; Schultz et al., 1997), little attempt 
has been made to try to relate the Einstellung findings to current psychological theory (McKelvie, 1990), or to personality.

The water-jar task (Luchins, 1942) was administered following a procedure advocated by Christie (1993). After an initial set of instructions, participants were shown how to solve one problem and then were asked to solve one sample problem on their own, during which time they were encouraged to ask questions. Following this, the participants were then given a maximum of 10 problems that could all be solved using the same solution: Jar B, minus Jar A, minus Jar C, minus Jar C. For instance, as shown in Table 1, to solve the first of the set problems using the set solution, a person would perform the following calculations:

$$
61-31=30 ; \quad 30-12=18 ; \quad 18-12=6
$$

The B -A- 2C set solution is one often used with the Einstellung water-jar task (McKelvie, 1990; Luchins \& Luchins, 1959).

Students worked on each problem until they solved it correctly or until their allotted time expired. Problems were presented until the participant correctly solved four consecutive problems with no deviation from the set solution-this was the criterion we adopted to indicate that a participant had established the mental set. Once the set was established, participants were presented with an extinction problem. It is called an extinction problem because the set response will not work. As shown in Table l, the solution is shorter and more direct (e.g., Jar A+Jar C). Participants who did not meet the set criteria by the 10th problem were given the extinction problem as their 11th problem. The time needed to solve each water-jar problem was recorded by the experimenter using a stopwatch.

Using this procedure, the water-jar task produced two types of problem solving measures. The first type of measure included (1) whether or not the participant developed set, and (2) the amount of time required to solve the four set problems given prior to the extinction problem. These more cognitive measures reflect a person's readiness to establish a solution pattern. The second type of measure was the time required to break the set (assuming it has formed). This measure reflects the perserverative aspect of problem solving, and more time needed indicates more perseveration.

\section{Procedure}

Participants began the study of completing a packet of surveys, one of which was the PNS scale. Each participant was then randomly assigned to either the stressful $(N$ $=86)$ or nonstressful $(N=86)$ experimental condition. The stressful manipulation asked the participant to work as quickly as possible, emphasized the importance of working quickly, and allowed only 2 min to solve each problem. In contrast, the non-stressful condition did not emphasize the importance of time, indicated that the time required to solve each problem would be recorded only to establish a baseline for another project, and allowed 4 min to solve each problem. In addition, participants in the stressful condition watched a $22 \mathrm{~cm}$ analog clock count down the $2 \mathrm{~min}$, at which point a loud buzzer sounded indicating that their time had expired. For participants in the non-stressful condition, the clock was present but not used (instead, the experimenter kept track of the time with a stopwatch and announced in a reasonable tone of voice if the 4 min time limit was reached).

Each participant completed the Einstellung water-jar task in an individual session with one of three experimenters. Following the experimental manipulation, 
participants were presented with each set problem on a separate sheet of paper and asked to show all their work in the space provided. The experimenter watched as the participant worked on each problem. After a person had achieved the criteria for developing set (or had completed the 10th problem without reaching set), the experimenter presented the extinction problem. In most cases, it was clear when a participant had formed the set because he or she would solve each problem very quickly, often in less than $10 \mathrm{~s}$. Every attempt was made to ensure that the participant did not suspect that the extinction problem was different from the set problems; it was presented as just another problem in the continuing series. Upon completion of the procedure, all participants were completely debriefed. They were informed as to the hypotheses of the study, allowed to ask any questions, and asked not to discuss the study with other students.

\section{RESULTS}

Participants who developed set (i.e., solved four problems in a row by the 10th problem using the B-A-2C solution) were assigned a score of I; those not forming set were given a score of 0 . Overall, 133 of the 172 participants formed set (69 in the stressful condition and 64 in the nonstressful), and 39 did not. To test the relationship between PNS and the tendency to develop set, point-biserial correlation coefficients were calculated between PNS scale scores and the dichotomous measure of set development (yes or no) under stressful and nonstressful conditions. As predicted, results showed a nonsignificant relationship in the nonstressful condition ( $\mathrm{rpb}=0.03 ; P>0.05 ; N=86$ ), and a significant positive relationship in the stressful condition (rpb $=0.32 ; P=0.003$; $N=86$ ). The difference between these correlations is statistically significant ( $\mathrm{Z}=$ 1.93; $P<0.05)$. Only under stressful conditions were people high in PNS more likely to form a mental set than people low in PNS.

To further examine the relationship between PNS and the tendency to develop set, we analysed the time required to solve the set problems. The number of set problems solved by each participant ranged from 4-10. To generate a comparable number across all participants, the number of seconds required to solve the four set problems presented prior to the extinction problem were summed. This measure reflects the speed with which the participant applied the set solution once it had been discovered. Analyses were performed only for the 133 participants who developed set. On average, participants in the nonstressful condition required $171 \mathrm{~s}(\mathbf{S D}=91)$ to solve the four final set problems, while those in the stressful condition required $136 \mathrm{~s}(\mathbf{S D}=57)$. Correlation coefficients were calculated between PNS scale scores and the time used to solve the set problems. In both experimental conditions, PNS was negatively related to the set time scores: $r=$ $0.26(P<0.05 ; N=64)$ in the nonstressful condition, $r=-0.27 ;(\boldsymbol{P}<0.05 ; N=69)$ in the stressful condition.

The amount of time required to break the set during the extinction problem (for the 133 who developed set) was also examined. Of the 64 participants in the nonstressful condition, only one failed to solve the extinction problem within the 240 s limit. This participant was assigned a time score of 240-the highest possible value within that condition. Of the 69 participants in the stressful condition that developed set, 18 failed to solve the extinction problem within the $120 \mathrm{~s} \mathrm{limit}$. These participants were assigned a time score of 120 . The average time required to 
break set and solve the extinction problem was $71 \mathrm{~s}$ in the nonstressful condition $(\mathbf{S D}=69)$ and $64 \mathrm{~s}$ in the stressful condition (SD = 42). Note that comparing the time required to break set with the average time required to solve each of the four final set problems $(171 / 4=43 \mathrm{~s}$ in the stressful condition, and 136/4 $=34 \mathrm{~s}$ in the non-stressful condition) shows the classic Einstellung effect.

To examine individual differences in perserveration, correlation coefficients were calculated between PNS scale scores and the number of seconds needed to break set and solve the extinction problem. Results showed no significant relationship in either the nonstressful $(r=-0.03 ; P>0.05 ; N=64)$ or stressful $(r=$ $0.11 ; P>0.05 ; N=69)$ conditions.

\section{DISCUSSION}

The tendency to develop a mental set on the Einstellung water-jar task measures the readiness with which a person adopts a patterned response. Conceptually, this tendency should be directly related to personal need for structure, given that PNS assesses individual differences in preference for clarity and certainty. Establishing a mental set leads to an increase in structure and a reduction in uncertainty. The present results clearly showed that personal need for structure was significantly (and positively) related to the tendency to develop set on the Einstellung water-jar task-but only for subjects who were in the stressful condition. These findings are consistent with recent research in suggesting an interaction between personality and situations where motives, heuristics, or schemas are activated through contextual cues (e.g., Brand et al., 1995; Moore et al., 1997; Schultz et al., 1997; Van Denburg \& Kiesler, 1993). Under nonstressful conditions, personal need for structure is not activated, and subsequently does not influence behavior.

In addition to the tendency to develop set, we found that PNS was negatively correlated with the time required to apply the set solution and solve the final four set problems-regardless of experimental condition. This suggests that participants high in PNS tend to apply the set solution quicker once it has been discovered. This tendency could help explain why high PNS participants were more likely to develop set only when they were in the stressful condition. When only $120 \mathrm{~s}$ was provided, high PNS participants were more likely to finish in the allotted time because they were quicker to apply the set solution than their low PNS counterparts. However, when 240 s were allowed for each problem in the nonstressful condition, no significant relationship was found between PNS and set development because low PNS participants had enough time to find and apply the set solution.

This explanation is consistent with the findings of Brand et al. (1995). In discussing the relationship between personality rigidity and problem solving, Brand et al. (1995) stated "under noisy conditions, the more rigid Ss responsed faster ... than the more flexible Ss, but this was clearly at the cost of accuracy" (p. 577). Our findings show that high PNS participants are quicker to find the set solution-a characteristic which is more advantageous in the stressful condition because of time constraints.

However, we do not find any evidence of more perseveration for high PNS participants. Perseveration measures the degree to which the person continues to apply the set solution when it is no longer effective, efficient, or optimal. Schultz et al. (1997) reported a significant relationship between authoritarian and perseveration on the Einstellung water-jar task only under ego-involved conditions. Given the positive correlation reported by Neuberg and Newsom (1993) between authoritarism and PNS, it could have been predicted that people high in PNS would be more likely to perseverate in their use of the set solution under stressful conditions. However, if the PNS scale primarily measures a desire for structure, the reverse prediction could also 
have been made. That is, if a person desires order and dislikes uncertainty, then as soon as the set solution failed to work, the high PNS person would immediately start seeking alternative set solution-leading to less perseveration. The results from the present study revealed no significant relationship-perhaps owing in part to the large amount of variability in the time required to solve the extinction problem- between PNS scores and the tendency for perseveration, under either stressful or nonstressful conditions.

Clearly our results point to a distinction between individual differences in the development of set and rigidity. The former measures the degree to which a person imposes a mental structure on his or her cognitions, while the latter refers to the perseveration of these mental structures. Schultz et al. (1997) proposed that physiological arousal, as a result of increased stress, was an important mediator between personality and rigid problem-solving behavior. It is possible that arousal mediates the relationship between authoritianism and perseveration. However, a broader interactional perspective would suggest that it may be enough to activate (c.f. Moore et al., 1997) the personality variable by creating experimental situations that are personally relevant, or that other- wise bring out individual differences in behavior. Activating authoritarianism with ego-involvement yields perserveration, whereas activating personal need for structure with time pressure yields a greater tendency to develop a cognitive set.

Acknowledgements-We thank Larry Daniels, Jennifer Jones. Holly Shoemaker, and Amy Tyo for their assistance with data collection. 


\section{REFERENCES}

Brand, N., Schneider, N., \& Arntz, P. (1995). Information processing efficiency and noise. Interactions with personal rigidity. Personality and Individual Differences, 18, 571-579.

Cacioppo, J. T., \& Petty, R. E. (1982). The need for cognition. Journal of Personality and Social Psychology, 42, I 1\&-131. Christie, R. (1993). Some experimental approaches to authoritianism: A retrospective perspective on the Einstellung (rigidity?)paradigm. In W. F. Stone, G. Lederer, \& R. Christie (Ed.), Strength and weakness: The authoritarian personality today (pp. 71-123). New York: Springer-Verlag.

Cohen, J. (1992). A power primer. Psychological Bulletin, 112, 155-159. Fiske, S. T., \& Taylor, S. E. (1991). Social cognition (2nd ed.). New York: McGraw-Hill.

Ford, T. E., \& Kruglanski, A. W. (1995). Effects of epistemic motivations on the use of accessible constructs in social judgment. Personality and Social Psychology Bulletin, 21, 950-962.

Freund, T., Kruglanski, A. W., \& Schpitzajzen, A. (1985). The freezing and unfreezing of impressional primacy: Effects of the need for structure and fear of invalidity. Personality and Social Psychology Bulletin, 11, 479-487.

Gough, H. G. (I 952). Rigidity as a psychological variable. Unpublished manuscript, University of California, Institute on Personality Assessment and Research, University of California Berkeley, CA.

Gough, H. G., \& Bradley, P. (1997). CPI manual (3rd ed.). Palo Alto, CA: Consulting Psychologists Press.

Jamieson, D. W., \& Zanna, M. (1989). Need for structure in attitude formation and expression. In A. R. Pratkanis, S. J. Breckler, \& A.G. Greenwald (Ed.), Attitude structure and function (pp. 383-406). Hillsdale, NJ: Erlbaum.

John, 0. P., Donahue, E., \& Kentle, R. J. (1991). The "Big Five" inventory: Versions $4 a$ and 54. Berkeley, CA: University of California, Institute of Personality Assessment and Research.

Kahneman, D. (1973). Attention and effort. Englewood Cliffs, NJ: Prentice-Hall.

Kruglanski, A. W. (1989). Lay epistemics and human knowledge: Cognitive and motivational bases. New York: Plenum. Kruglanski, A. W., \& Freund, T. (1983). The freezing and unfreezing of lay inferences: Effects on impressional primacy, ethnic stereotyping, and numberical anchoring. Journal of Experimental Social Psychology, 19, 448-468.

Luchins, A. S. (1942). Mechanization in problem solving. Psychological Monographs, 54, No. 6 (Whole No. 248).

Luchins, A. S., \& Luchins, E. H. (I 959). Rigidity of behavior: A variational approach to the effect of Einstellung. Eugene, OR: University of Oregon Books.

Luchins, A. S., \& Luchins, E. H. (1982). Einstellung effects in learning by repetition: Sex differences. Psychological Mono- graphs, 106, 319-342.

Luchins, A. S., \& Luchins, E. H. (1984). Sex differences in reasons given for responses to the water-jar problems. Journal of Psychology, 118, 207-220.

Luchins, A. S., \& Luchins, E. H. (1989). Computer simulation, algorithms, and heuristics in Einstellung effects. Genetic, Social and General Psychology Monographs, 115, 51-80.

Luchins, A. S., \& Luchins, E. H. (1994). The water jar experiment and einstellung effects. Gestalt Theory, 16, 101-121. Maier, N. R. F. (1930). Reasoning in 
humans. On direction. Journal of Comparative Psychology, JO, 115--143.

McCrae, R. R., Costa, P. T., Jr., \& Piedmont, R. L. (1993). Folk concepts, natural language, and psychological constructs: The California Psychological Inventory and the five-factor model. Journal of Personality, 61, 1-26.

McKelvie, S. (1990). Einstellung: Luchins' effect lives on. Journal of Social Behavior and Personality, 5, 105-121.

Moore, S. R., Smith, R. E., \& Gonzalez, R. (1997). Personality and judgment heuristics: Contextual and individual difference interactions in social judgment. Personality and Social Psychology Bulletin, 23, 7\&-83.

Moskowitz, B. (1993). Individual differences in social catogorization: The influence of personal need for structure on spontaneous trait inferences. Journal of Personality and Social Psychology, 65, 132-142.

Neuberg, S., Judice, T. N., \& West, S. (in press). What the need for closure scale measures and what it does not: Toward differentiating among related epistemic motives. Journal of Personality and Social Psychology.

Neuberg, S., \& Newsom, J. (1993). Personal need for structure: Individual differences in the desire for simple structure. Journal of Personality and Social Psychology, 65, 113-131.

Pashler, H. (1992). Attentional limitations in doing two tasks at the same time. Current Directions in Psychological Science, 1, 44-64.

Rokeach, M. (1960). The open and closed mind: Investigations into the nature of belief systems and personality. New York: Basic Books.

Schaller, M., Boyd, C., Yohannes, J., \& O'Brien, M. (1995). The prejudiced personality revisited: Personal need for structure and formation of erroneous group stereotypes. Journal of Personality and Social Psychology, 68, 544-555.

Schultz, P. W., Stone, W. F., \& Christie, R. (1997). Authoritarianism and mental rigidity: The Einstellung problem revisited. Personality and Social Psychology Bulletin, 23, 3-9.

Smith, A. (1990). Stress and information processing. In M. Johnston \& L. Wallace (Ed.), Stress and medical procedures (pp. 58-79). Oxford, England: Oxford University Press.

Thompson, E. P., Roman, R. J., Moskowitz, G. B., Chaiken, S., \& Bargh, J. A. (1994). Accuracy motivation attenuates covert priming effects: The systematic reprocessing of social information. Journal of Personality and Social Psychology, 66, 474-489.

Thompson, M. M., Naccarato, M. E., \& Parker, K. E. (1989). Assessing cognitive need: The development of the Personal Need for Structure and Personal Fear of Invalidity scales. Paper presented at the annual meeting of the Canadian Psychological Association, Halifax, Nova Scotia.

Van Denburg, T., \& Kielser, D. (1993). Transactional escalation in rigidity and intensity of interpersonal behavior under stress. British Journal of Medical Psychology, 66, 15-31. 